\title{
Perencanaan dan Pengendalian Persediaan Bahan Baku serta Komponen Mbox di PT. X
}

\author{
Alif Nurul Hidayah ${ }^{1 *}$ \\ ${ }^{1}$ Jurusan Teknik Industri, Fakultas Sains dan Teknologi, Universitas Ma Chung \\ Villa Puncak Tidar N-01, Malang, \\ *Email: alifnurul1997@gmail.com
}

DOI: 10.25042/jpe.112019.12

\begin{abstract}
Abstrak
Perkembangan dunia perindustrian kini semakin pesat pasalnya perusahaan saling berkompetisi untuk unggul dibidangnya. Perusahaan dapat bertahan di tengah persaingan apabila perusahaan mampu melakukan peningkatan efisiensi. Salah satu caranya adalah dengan mengendalikan persediaan. Penelitian ini dilakukan untuk membuat perencanaan dan pengendalian kebutuhan optimal komponen serta bahan baku pada PT X dengan menerapkan metode Algoritma Wagner Within untuk tercapainya target produksi pembuatan Mbox. Jenis bahan baku serta komponen dalam membentuk satu unit produk Mbox terdiri dari 18 jenis komponen serta 6 jenis bahan baku. Pengolahan data akan dilakukan dengan melakukan penetapan permintaan Mbox setiap periode. Setelah itu dilakukan perhitungan biaya pengendalian persediaan melalui 3 langkah metode Algoritma Wagner Within. Dari hasil perhitungan diperoleh ukuran lot pemesanan yang menghasilkan ongkos total persediaan sebesar Rp. 54.109.030 dengan produksi komponen setiap periode harus terpenuhi dan pemesanan bahan baku dilakukan pada awal periode untuk memenuhi kebutuhan produksi seluruh periode. Kecuali pemesanan plat baja 1,5 mm yang dipesan 6 kali. Adanya perbedaan tersebut dikarenakan adanya hasil perhitungan dari metode Algoritma Wagner Within yang mengharuskan pemesanan dilakukan pada periode-periode tertentu.
\end{abstract}

\begin{abstract}
Planning and Controlling Raw Material Inventory and Mbox Components at PT. X. The development of the industrial now increasingly rapid because the companies compete each other to be excellent in their fields. Companies can survive in the midst of competition if the company is able to increase efficiency. One of the way is to control inventory. This research was conducted to make the planning and control of the optimal needs of raw material and component at PT. X by applying the Wagner Within Algorithm method to achieve the Mbox production target. Types of raw materials and component in forming one Mbox product unit consist 18 types of component and 6 types of raw materials. Data processing will be done by setting the Mbox request every period. After that, inventory control costs are calculated using the 3 step Wagner Within Algorithm method. From the calculation results obtained by order lot size which results in a total inventory cost of Rp. 54.109.030. with component production every period must be fulfilled and raw material ordering is done at the beginning of the period to meet the production needs to entire period. Except for 1,5 $\mathrm{mm}$ steel plate order, which are ordered 6 times. The difference is due the calculation results from the Wagner Within Algorithm method which requires bookings made at certain periods.
\end{abstract}

Kata Kunci: Algoritma Wagner Within, persediaan bahan baku, lot sizing

\section{Pendahuluan}

Perkembangan dunia perindustrian kini semakin pesat pasalnya perusahaan saling berkompetisi untuk unggul dibidangnya. Hanya perusahaan yang mampu menekan biaya produksi seminimal mungkin dengan tanpa mengurangi kualitas produk yang dapat bertahan ditengah persaingan yang semakin ketat. Salah satunya adalah dengan cara meningkatkan efisiensi dengan jalan mengendalikan persediaan. Perusahaan yang dihadapkan dengan permasalahan kebijakan inventory saat ini salah satunya dialami oleh PT X. PT X merupakan satu-satunya perusahaan yang dimiliki dalam negeri, maka dari itu guna memenuhi penyediaan alat dan peralatan keamanan serta pertahanan dalam operasionalnya perencanaan dan pengendalian dalam proses produksi harus diperhatikan dengan baik.

Selain memproduksi amunisi sebagai produk utama juga memproduksi produk pendukung seperti bahan peledak, rel kereta api, perkakas serta kotak amunisi. Ada tiga jenis kotak yang digunakan sebagai kemasan amunisi yaitu kotak 260 yang terbuat dari bahan plastik, kotak yang 
terbuat dari kayu serta kotak Mbox yang terbuat dari plat baja.

Berdasarkan hasil observasi pada perusahaan diketahui proses produksi kotak yang terbuat dari bahan plastik tidak mengalami masalah karena bahan dasar plastik merupakan hasil pembelian sehingga hanya membutuhkan pemasangan pengunci kotak, begitupun dengan kotak kayu sebagai kemasan amunisi berukuran besar dan produksi kotak kayu terbatas karena permintaan juga sedikit, namun terdapat masalah pada kotak amunisi yang terbuat dari plat baja dengan target produksi yang tidak dapat tercapai selama 3 tahun terakhir yaitu pada tahun 2016 target produksi 12.000 unit hanya tercapai 11.376 unit, tahun 2017 target produksi 20.000 unit target tercapai 19.560 unit serta pada tahun 2018 target produksi sebanyak 15.000 unit hanya mencapai 13.896 unit. Hal ini mengakibatkan perusahaan mengalami kerugian dengan menanggung biaya denda kepada konsumen.

Penelitian yang bertujuan untuk merencanakan dan mengendalikan kebutuhan dari produk pendukung PT X yakni Mbox dengan jumlah komponen serta bahan baku yang dibutuhkan dalam proses pembuatan yang harus tersedia agar dapat menghasilkan bahan material secara optimal bagi PT X terutama produk pendukung Mbox.

Menurut Ampuh [1] mengemukakan definisi persediaan sebagai sejumlah barang yang disimpan guna menunjang kelancaran kegiatan produksi dan distribusi yang berwujud barang yang disimpan dalam keadaan menunggu atau belum selesai dikerjakan. Pada umumnya persediaan memiliki tujuan untuk menghilangkan berbagai kemungkinan yang dapat menyebabkan kekurangan stok, permintaan yang tidak terduga, terjadinya kenaikan harga dan kemungkinan lain yang sifatnya dapat menghambat laju produksi. Sedangkan ditinjau dari tujuannya menurut pendapat dari Assauri [2] tujuan dari pengendalian persediaan dapat diartikan sebagai bentuk usaha menjaga jangan sampai perusahaan kehabisan persediaan yang menyebabkan proses produksi terhenti, menjaga agar penentuan persediaan perusahaan tidak terlalu besar sehingga biaya yang berkaitan dengan persediaan dapat ditekan dan menghindari pembelian bahan baku secara kecil-kecilan.

Perencanaan dan pengendalian persediaan bertujuan untuk mendapatkan tingkat pelayanan dengan biaya yang minimum dengan hasil yang optimal. Menurut Tampubolon [3] terdapat biaya-biaya yang timbul dari adanya persediaan yang dapat diklasifiksikan menjadi empat golongan, yaitu biaya pemesanan (Ordering cost), biaya penyimpanan (Carrying cost), biaya pengadaan persediaan (Stock holding cost), dan biaya kehabisan persedian (Stockout cost).

\section{Metode Penelitian}

Algoritma Wagner Within (AWW) dikembangkan oleh Wagner dan Within tahun 1958 dimana algoritma ini digunakan untuk menyelesaikan persoalan ukuran pemesanan deterministik pada suatu kurun waktu tertentu dimana kebutuhan seluruh periode harus terpenuhi. Selain itu tujuan dari penggunaan teknik ini adalah untuk mendapatkan total biaya yang paling minimum karena menggunakan program dinamis dan pendekatan matematisnya yang sangat detail serta strategi pemesanan yang optimal untuk seluruh jadwal kebutuhan bersih dengan jalan meminimalisi total ongkos pengadaan dan ongkos simpan. Langkahlangkah AWW [4] yaitu pertama dengan menghitung matrik biaya total (biaya pesan dan biaya simpan) terlebih dahulu, selanjutnya didefinisikan sebagai $Z_{c e}$ dengan rumusan sebagai berikut:

$$
\begin{gathered}
Z_{c e}=C+h P \\
\sum_{i=e}^{e}\left(Q_{c e}-Q_{c i}\right)
\end{gathered}
$$

untuk $1 \leq \mathrm{c} \leq \mathrm{e} \leq \mathrm{N}$.

Dimana:

$$
\begin{array}{ll}
\mathrm{C} & : \text { Biaya pesan }(\mathrm{Rp} / \mathrm{pesan}) \\
\mathrm{h} & : \text { Biaya simpan per unit per periode } \\
& \text { (Rp/unit/periode) } \\
\mathrm{P} & : \text { Biaya pembelian unit } \\
Q_{c e}: & \sum_{k=c}^{e}=R_{k} \\
R_{k} & : \text { tingkat permintaan dalam periode }
\end{array}
$$

Selanjutnya menentukan nilai $f_{n}$ yaitu nilai biaya total dan pemesanan optimal yang dihitung dengan menggunakan formula berikut: 


$$
f_{n}=\operatorname{Min}\left[Z_{c e}+f_{e-1}\right]
$$

Untuk c $=1,2, \ldots, \mathrm{e}$

Langkah terakhir yaitu menghitung solusi optimal $f T$ dapat diperoleh dari perhitungan rekursif mundur sebagai berikut:

$$
f_{n}=Z_{w n}+f_{w-1}
$$

Pemesanan terakhir dilakukan pada periode e untuk memenuhi permintaan dari periode e sampai periode $\mathrm{N}$.

$$
f_{w-1}=Z_{v w-1}+f_{v-1}
$$

Pemesanan sebelum pemesanan terakhir harus dilakukan pada periode $\mathrm{v}$ untuk memenuhi permintaan dari periode $\mathrm{v}$ sampai periode $\mathrm{w}-1$.

$$
f_{w-1}=Z_{1 u-1}+f_{0}
$$

Pemesanan yang pertama harus dilakukan pada periode 1 untuk memenuhi permintaan dari periode 1 sampai $\mathrm{u}-1$.

\section{Hasil dan Pembahasan}

Berikut ini akan dilakukan pengolahan data dengan menggunakan teknik lotting Wagner Within Algorithm. Dengan Master Product Scheduling (MPS) yang di tampilkan pada Tabel 1 dan 2 serta biaya simpan dan biaya pesan pada Tabel 3 dan 4.

Tabel 1. Data MPS kebutuhan produksi komponen Mbox

\begin{tabular}{lllllll}
\hline Nama Item/bulan & Ke-1 & Ke-2 & Ke-3 & Ke-4 & Ke-5 & Ke-6 \\
\hline Mbox & 5000 & 5000 & 7500 & 7500 & 2500 & 2500 \\
Mbox marking & 5000 & 5000 & 7500 & 7500 & 2500 & 2500 \\
Assembling Mbox & 5000 & 5000 & 7500 & 7500 & 2500 & 2500 \\
Silk tutup & 5000 & 5000 & 7500 & 7500 & 2500 & 2500 \\
Pengecatan tutup & 5000 & 5000 & 7500 & 7500 & 2500 & 2500 \\
Pengecatan badan & 5000 & 5000 & 7500 & 7500 & 2500 & 2500 \\
Tutup lengkap & 5000 & 5000 & 7500 & 7500 & 2500 & 2500 \\
Badan lengkap & 5000 & 5000 & 7500 & 7500 & 2500 & 2500 \\
Lapisan tutup & 5000 & 5000 & 7500 & 7500 & 2500 & 2500 \\
Plat pengunci & 5000 & 5000 & 7500 & 7500 & 2500 & 2500 \\
Tutup Mbox & 5000 & 5000 & 7500 & 7500 & 2500 & 2500 \\
Rumah penjinjing & 5000 & 5000 & 7500 & 7500 & 2500 & 2500 \\
Pegangan & 5000 & 5000 & 7500 & 7500 & 2500 & 2500 \\
penjinjing & 5000 & 5000 & 7500 & 7500 & 2500 & 2500 \\
Engsel tutup & 5000 & 5000 & 7500 & 7500 & 2500 & 2500 \\
Dinding badan & 5000 & 5000 & 7500 & 7500 & 2500 & 2500 \\
Plat dasar & 5000 & 5000 & 7500 & 7500 & 2500 & 2500 \\
Engsel badan & 5000 & 5000 & 7500 & 7500 & 2500 & 2500 \\
Penahan kunci & 5000 & 5000 & 7500 & 7500 & 2500 & 2500 \\
Pegangan & 5000 & 5000 & 7500 & 7500 & 2500 & 2500 \\
Rumah pengunci & 5000 & 5000 & 7500 & 7500 & 2500 & 2500 \\
Penyambung & 5000 & 5000 & 7500 & 7500 & 2500 & 2500 \\
penjinjing & 5000 & 5000 & 7500 & 7500 & 2500 & 2500 \\
Pena engsel & & & & & \\
Kawat pengunci & 500 &
\end{tabular}


Tabel 2. Data MPS kebutuhan produksi bahan baku Mbox

\begin{tabular}{lcccccc}
\hline \multicolumn{1}{c}{ Nama Item/bulan } & Ke-1 & Ke-2 & Ke-3 & Ke-4 & Ke-5 & Ke-6 \\
\hline Plat baja $0,5 \mathrm{~mm}$ & 875 & 875 & 875 & 875 & 875 & 875 \\
Plat baja $1 \mathrm{~mm}$ & 13387 & 13387 & 13387 & 13387 & 13387 & 13387 \\
Plat baja $1,5 \mathrm{~mm}$ & 3033 & 3033 & 3033 & 3033 & 3033 & 3033 \\
Kawat baja $3 \mathrm{~mm}$ & 263 & 263 & 263 & 263 & 263 & 263 \\
Kawat baja $4 \mathrm{~mm}$ & 478 & 478 & 478 & 478 & 478 & 478 \\
Kawat baja $4,5 \mathrm{~mm}$ & 12 & 12 & 12 & 12 & 12 & 12 \\
\hline
\end{tabular}

Tabel 3. Biaya pesan dan biaya simpan komponen Mbox

\begin{tabular}{|c|c|c|}
\hline Nama Item & Biaya Simpan & Biaya Set up \\
\hline Mbox & Rp 2.000,00 & $\operatorname{Rp} 300.000,00$ \\
\hline Mbox marking & $\operatorname{Rp} 2.000,00$ & $\operatorname{Rp} 300.000,00$ \\
\hline Assembling Mbox & Rp 2.000,00 & Rp 300.000,00 \\
\hline Silk tutup & Rp 2.000,00 & Rp $300.000,00$ \\
\hline Pengecatan tutup & Rp 2.000,00 & Rp 300.000,00 \\
\hline Pengecatan badan & Rp 2.000,00 & Rp 300.000,00 \\
\hline Tutup lengkap & Rp 1.500,00 & Rp 500.000,00 \\
\hline Badan lengkap & Rp 1.200,00 & Rp 400.000,00 \\
\hline Lapisan tutup & Rp 1.100,00 & Rp 400.000,00 \\
\hline Plat pengunci & Rp 1.300,00 & Rp 500.000,00 \\
\hline Tutup Mbox & Rp 1.100,00 & Rp 300.000,00 \\
\hline Rumah penjinjing & Rp 1.000,00 & $\mathrm{Rp} 400.000,00$ \\
\hline Pegangan penjinjing & Rp 1.200,00 & Rp 400.000,00 \\
\hline Engsel tutup & Rp 1.100,00 & Rp 300.000,00 \\
\hline Dinding badan & Rp 1.100,00 & Rp 300.000,00 \\
\hline Plat dasar & Rp 1.100,00 & Rp 300.000,00 \\
\hline Engsel badan & Rp 1.300,00 & Rp 500.000,00 \\
\hline Penahan kunci & Rp 1.100,00 & Rp 300.000,00 \\
\hline Pegangan & Rp 1.100,00 & Rp 400.000,00 \\
\hline Rumah pengunci & Rp 1.100,00 & Rp 300.000,00 \\
\hline Penyambung penjinjing & Rp 1.000,00 & Rp 400.000,00 \\
\hline Pena engsel & $\operatorname{Rp} 600,00$ & Rp 300.000,00 \\
\hline Kawat pengunci & $\operatorname{Rp} 1.100,00$ & $\operatorname{Rp} 300.000,00$ \\
\hline
\end{tabular}

Tabel 4. Biaya pesan dan biaya simpan bahan baku Mbox

\begin{tabular}{|c|c|c|}
\hline Nama Item & Biaya Simpan & Biaya pesan \\
\hline Plat baja $0,5 \mathrm{~mm}$ & $\operatorname{Rp} 300,000$ & Rp 900.000,00 \\
\hline Plat baja $1 \mathrm{~mm}$ & $\operatorname{Rp} 400,00$ & Rp $1.200 .000,00$ \\
\hline Plat baja $1,5 \mathrm{~mm}$ & $\operatorname{Rp} 500,00$ & $\operatorname{Rp} 800.000,00$ \\
\hline Kawat baja $3 \mathrm{~mm}$ & $\operatorname{Rp} 600,00$ & $\operatorname{Rp} 800.000,00$ \\
\hline Kawat baja $4 \mathrm{~mm}$ & $\operatorname{Rp} 600,00$ & $\operatorname{Rp} 2.300 .000,00$ \\
\hline Kawat baja $4,5 \mathrm{~mm}$ & $\operatorname{Rp} 600,00$ & $\operatorname{Rp} 700.000,00$ \\
\hline
\end{tabular}

Langkah pertama: Menghitung matriks biaya total persediaan sesuai dengan Persamaan 1 untuk semua alternatif pemesanan selama 6 periode perencanaan pada tahun 2019. Biaya simpan Rp. 2.000 dan biaya pesan Rp. 300.000.
Tabel 5. Data MPS kebutuhan produksi komponen Mbox

\begin{tabular}{lcccccc}
\hline $\begin{array}{c}\text { Nama } \\
\text { Item/bulan }\end{array}$ & Ke-1 & Ke-2 & Ke-3 & Ke-4 & Ke-5 & Ke-6 \\
\hline Mbox & 5000 & 5000 & 7500 & 7500 & 2500 & 2500 \\
\hline
\end{tabular}


Perhitungan matriks untuk biaya total Mbox adalah sebagai berikut:

$$
\begin{aligned}
\mathrm{Z}_{1,1}= & 300.000+2.000((5000-5000))= \\
& 300.000 \\
\mathrm{Z}_{1,2}= & 300.000+2.000((10000-5000)+ \\
& (10000-10000))=10.300 .000 \\
\mathrm{Z}_{1,3}= & 300.000+2.000((17500-5000)+ \\
& (17500-10000)+(17500-17500)) \\
= & 25.307 .500
\end{aligned}
$$$$
\mathrm{Z}_{1,4}=300.000+2.000((25000-5000)+
$$$$
(25000-10000)+(25000-17500)
$$$$
+(25000-25000))=40.322 .500
$$

$\mathrm{Z}_{1,5}=300.000+2.000((27500-5000)+$ $(27500-10000)+(27500-17500)$ $+(27500-25000)+(27500-$ $27500))=45.330 .500$

$\mathrm{Z}_{1,6}=300.000+2.000((30000-5000)+$ $(30000-10000)+(30000-17500)$ $+(30000-25000)+(30000-$ $27500)+(30000-30000))=$ 50.340 .000

$\mathrm{Z}_{2,2}=300.000+2.000((5000-5000))=$ 300.000

$\mathrm{Z}_{2,3}=300.000+2.000((12500-5000)+$ $(12500-12500))=15.300 .000$

$\mathrm{Z}_{2,4}=300.000+2.000((20000-5000)+$ $(20000-12500)+(20000-20000))$ $=30.307 .500$

$\mathrm{Z}_{2,5}=300.000+2.000((22500-5000)+$ $(22500-12500)+(22500-20000)$

$+(22500-22500))=35.312 .500$

$\mathrm{Z}_{2,6}=300.000+2.000((25000-5000)+$ $(25000-10000)+(25000-17500)$ $+(25000-25000)+(25000-$ $25000))=40.320 .000$

$Z_{3,3}=300.000+2.000((7500-7500))=$ 300.000

$\mathrm{Z}_{3,4}=300.000+2.000((15000-7500)+$ $(15000-15000))=15.300 .000$

$\mathrm{Z}_{3,5}=300.000+2.000((17500-7500)+$ $(17500-15000)+(17500-17500))$ $=20.302 .500$

$\mathrm{Z}_{3,6}=300.000+2.000((20000-7500)+$ $(20000-15000)+(20000-17500)$ $+(20000-20000))=25.307 .500$

$\mathrm{Z}_{4,4}=300.000+2.000((7500-7500))=$ 300.000

$\mathrm{Z}_{4,5}=300.000+2.000((10000-7500)+$ $(10000-10000))=5.300 .000$

$\mathrm{Z}_{4,6}=300.000+2.000((12500-7500)+$ $(12500-10000)+(12500-12500))$ $=10.302 .500$

$$
\begin{aligned}
\mathrm{Z}_{5,5}= & 300.000+2.000((2500-2500))= \\
& 300.000 \\
\mathrm{Z}_{5,6}= & 300.000+2.000((5000-2500)+ \\
& (5000-5000))=5.300 .000 \\
\mathrm{Z}_{6,6}= & 300.000+2.000((2500-2500))= \\
& 300.000
\end{aligned}
$$

Langkah kedua : Berdasarkan Persamaan 2, langkah berikutnya adalah menghitung $f_{n}$ sebagai biaya minimum yang mungkin dalam periode 1 sampai periode 6 , dengan asumsi tingkat persediaan akhir periode $\mathrm{n}$ adalah nol. Biaya minimum yang mungkin dapat dihitung sebagai berikut:

$$
\begin{array}{rl}
f_{0}= & 0 \\
f_{1}= & \operatorname{Min}\left(Z_{11}+f_{0}\right)=(300.000+0) \\
= & 300.000 \text { untuk } Z_{11}+f_{0} \\
f_{2}= & \operatorname{Min}\left(Z_{12}+f_{0}, Z_{22}+f_{1}\right)=\text { Min } \\
& (10.300 .000+0,300.000+300.000) \\
= & 600.000 \text { untuk } Z_{22}+f_{1} \\
f_{3}= & \operatorname{Min}\left(Z_{13}+f_{0}, Z_{23}+f_{1}, Z_{33}+f_{2}\right)=\operatorname{Min} \\
& (25.307 .500+0, \quad 15.300 .000+ \\
& 300.000,300.000+600.000) \\
= & 900.000 \text { untuk } Z_{33}+f_{2} \\
= & \operatorname{Min}\left(Z_{14}+f_{0}, Z_{24}+f_{1}, Z_{34}+f_{2}, Z_{44}+\right. \\
& \left.f_{3}\right)=\quad \operatorname{Min}(40.322 .500+\quad 0, \\
& 30.307 .500+300.000,15.300 .000+ \\
& 600.000,300.000+900.000) \\
= & 1.200 .000 \text { untuk } Z_{44}+f_{3} \\
= & \operatorname{Min}\left(Z_{15}+f_{0}, Z_{25}+f_{1}, Z_{35}+f_{2}, Z_{45}+\right. \\
& \left.f_{3}, Z_{55}+f_{4}\right)=\operatorname{Min}(45.330 .500+0, \\
& 35.312 .500+300.000,20.302 .500+ \\
& 600.000, \quad 5.300 .000 \quad+900.000, \\
& 300.000+1.200 .000) \\
= & 1.500 .000 \text { untuk } Z_{55}+f_{4} \\
= & \operatorname{Min}\left(Z_{16}+f_{0}, Z_{26}+f_{1}, Z_{36}+f_{2}, Z_{46}+\right. \\
& \left.f_{3}, \quad Z_{56}+f_{4}, \quad Z_{66}+f_{5}\right)=\operatorname{Min} \\
& (50.340 .000+\quad 0, \quad 40.320 .000+ \\
& 300.000, \quad 25.307 .500+600.000, \\
& 10.302 .500+900.000,5.300 .000+ \\
& 1.200 .000,300.000+1.500 .000) \\
f_{6} & 1.800 .000 \text { untuk } Z_{66}+f_{5} \\
f_{5} & +
\end{array}
$$

Pada langkah kedua, telah diketahui bahwa biaya persediaan terendah sebesar 1.800.000. biaya tersebut merupakan biaya yang timbul akibat melakukan produksi untuk setiap bulannya.

Langkah ketiga : Menerjemahkan $f_{N}$ menjadi ukuran lot/solusi optimum kuantitas pemesanan yang diperoleh hasilnya sebagai berikut: 
- Solusi optimal ada pada kombinasi $f_{6}=Z_{66}+$ $f_{5}$, berarti bahwa ukuran lot pemesanan sebesar 2500 unit dilakukan pada periode 6 untuk memenuhi periode 6 , untuk pemesanan periode sebelumnya bergantung pada $f_{5}$.

- $f_{5}=Z_{55}+f_{4}$ berarti bahwa ukuran lot pemesanan sebesar 2500 unit dilakukan pada periode 5 untuk memenuhi periode 5 , untuk pemesanan periode sebelumnya bergantung pada $f_{4}$.

- $F_{4}=Z_{44}+f_{3}$ berarti bahwa ukuran lot pemesanan sebesar 7500 unit dilakukan pada periode 4 untuk memenuhi periode 4 , untuk pemesanan periode sebelumnya bergantung pada $f_{3}$.

- $F_{3}=Z_{33}+f_{2}$ berarti bahwa ukuran lot pemesanan sebesar 7500 unit dilakukan pada periode 3 untuk memenuhi periode 3 , untuk pemesanan periode sebelumnya bergantung pada $f_{2}$.

- $F_{2}=Z_{22}+f_{1}$ berarti bahwa ukuran lot pemesanan sebesar 5000 unit dilakukan pada periode 2 untuk memenuhi periode 2 , untuk pemesanan periode sebelumnya bergantung pada $f_{l}$.
- $f_{1}=Z_{11}+f_{0}$ berarti bahwa ukuran lot pemesanan sebesar 5000 unit dilakukan pada periode 1 untuk memenuhi periode 1 .

Rincian biaya total persediaan hasil studi dengan menggunakan Algoritma Wagner Within adalah seperti pada tabel berikut:

Tabel 6. Penentuan lot pemesanan Mbox dengan AWW

\begin{tabular}{lcccccc}
\hline Period/bulan & Ke-1 & Ke-2 & Ke-3 & Ke-4 & Ke-5 & Ke-6 \\
\hline $\begin{array}{l}\text { Demand } \\
\begin{array}{l}\text { Order } \\
\text { Quantity }\end{array}\end{array}$ & 5000 & 5000 & 7500 & 7500 & 2500 & 2500 \\
\hline
\end{tabular}

Pada Tabel 6 menunjukkan bahwa dengan menggunakan algoritma wagner within waktu pemesanan Mbox untuk tahun 2019 dilakukan sebanyak 6 kali yaitu pada periode 1 untuk memenuhi permintaan periode 1 sebanyak 5000 unit, periode 2 untuk memenuhi permintaan periode 2 sebanyak 5000 unit, periode 3 untuk memenuhi permintaan periode 3 sebanyak 7500 unit, periode 4 untuk memenuhi permintaan periode 4 sebanyak 7500 unit, periode 5 untuk memenuhi permintaan periode 5 sebanyak 2500 unit, periode 6 untuk memenuhi permintaan periode 6 sebanyak 2500 unit.

Tabel 7. Summary lot size order quantity komponen Mbox

\begin{tabular}{|c|c|c|c|c|c|c|c|}
\hline Item/bulan & & Ke-1 & Ke-2 & $\mathrm{Ke}-3$ & $\mathrm{Ke}-4$ & Ke-5 & Ke-6 \\
\hline \multirow{2}{*}{ Mbox } & Demand & 5000 & 5000 & 7500 & 7500 & 2500 & 2500 \\
\hline & Order quantity & 5000 & 5000 & 7500 & 7500 & 2500 & 2500 \\
\hline \multirow{2}{*}{ Tutup lengkap } & Demand & 5000 & 5000 & 7500 & 7500 & 2500 & 2500 \\
\hline & Order quantity & 5000 & 5000 & 7500 & 7500 & 2500 & 2500 \\
\hline \multirow{2}{*}{ Badan lengkap } & Demand & 5000 & 5000 & 7500 & 7500 & 2500 & 2500 \\
\hline & Order quantity & 5000 & 5000 & 7500 & 7500 & 2500 & 2500 \\
\hline \multirow{2}{*}{ Lapisan tutup } & Demand & 5000 & 5000 & 7500 & 7500 & 2500 & 2500 \\
\hline & Order quantity & 5000 & 5000 & 7500 & 7500 & 2500 & 2500 \\
\hline \multirow{2}{*}{ Plat pengunci } & Demand & 5000 & 5000 & 7500 & 7500 & 2500 & 2500 \\
\hline & Order quantity & 5000 & 5000 & 7500 & 7500 & 2500 & 2500 \\
\hline \multirow{2}{*}{ Tutup Mbox } & Demand & 5000 & 5000 & 7500 & 7500 & 2500 & 2500 \\
\hline & Order quantity & 5000 & 5000 & 7500 & 7500 & 2500 & 2500 \\
\hline \multirow{2}{*}{ Rumah penjinjing } & Demand & 10000 & 10000 & 15000 & 15000 & 5000 & 5000 \\
\hline & Order quantity & 10000 & 10000 & 15000 & 15000 & 5000 & 5000 \\
\hline \multirow{2}{*}{ Pegangan penjinjing } & Demand & 5000 & 5000 & 7500 & 7500 & 2500 & 2500 \\
\hline & Order quantity & 5000 & 5000 & 7500 & 7500 & 2500 & 2500 \\
\hline \multirow{2}{*}{ Engsel tutup } & Demand & 5000 & 5000 & 7500 & 7500 & 2500 & 2500 \\
\hline & Order quantity & 5000 & 5000 & 7500 & 7500 & 2500 & 2500 \\
\hline \multirow{2}{*}{ Dinding badan } & Demand & 5000 & 5000 & 7500 & 7500 & 2500 & 2500 \\
\hline & Order quantity & 5000 & 5000 & 7500 & 7500 & 2500 & 2500 \\
\hline
\end{tabular}




\begin{tabular}{llcccccc}
\hline \multicolumn{1}{c}{ Item/bulan } & & Ke-1 & Ke-2 & Ke-3 & Ke-4 & Ke-5 & Ke-6 \\
\hline \multirow{2}{*}{ Plat dasar } & Demand & 5000 & 5000 & 7500 & 7500 & 2500 & 2500 \\
& Order quantity & 5000 & 5000 & 7500 & 7500 & 2500 & 2500 \\
\hline \multirow{2}{*}{ Engsel badan } & Demand & 5000 & 5000 & 7500 & 7500 & 2500 & 2500 \\
& Order quantity & 5000 & 5000 & 7500 & 7500 & 2500 & 2500 \\
\multirow{2}{*}{ Penahan kunci } & Demand & 5000 & 5000 & 7500 & 7500 & 2500 & 2500 \\
& Order quantity & 5000 & 5000 & 7500 & 7500 & 2500 & 2500 \\
\hline \multirow{2}{*}{ Pegangan } & Demand & 5000 & 5000 & 7500 & 7500 & 2500 & 2500 \\
& Order quantity & 5000 & 5000 & 7500 & 7500 & 2500 & 2500 \\
\hline \multirow{2}{*}{ Rumah pengunci } & Demand & 5000 & 5000 & 7500 & 7500 & 2500 & 2500 \\
& Order quantity & 5000 & 5000 & 7500 & 7500 & 2500 & 2500 \\
\hline \multirow{2}{*}{ Penyambung penjinjing } & Demand & 10000 & 10000 & 15000 & 15000 & 5000 & 5000 \\
& Order quantity & 10000 & 10000 & 15000 & 15000 & 5000 & 5000 \\
\hline \multirow{2}{*}{ Pena engsel } & Demand & 20000 & 20000 & 30000 & 30000 & 10000 & 10000 \\
& Order quantity & 20000 & 20000 & 30000 & 30000 & 10000 & 10000 \\
\hline \multirow{2}{*}{ Kawat pengunci } & Demand & 5000 & 5000 & 7500 & 7500 & 2500 & 2500 \\
& Order quantity & 5000 & 5000 & 7500 & 7500 & 2500 & 2500 \\
\hline
\end{tabular}

Tabel 8. Summary lot size order quantity bahan baku Mbox

\begin{tabular}{cccccccc}
\hline Item/bulan & & Ke-1 & Ke-2 & Ke-3 & Ke-4 & Ke-5 & Ke-6 \\
\hline \multirow{2}{*}{ Plat baja 0,5 mm } & Demand & 875 & 875 & 875 & 875 & 875 & 875 \\
& Order quantity & 5250 & 0 & 0 & 0 & 0 & 0 \\
\hline \multirow{2}{*}{ Plat baja 1 mm } & Demand & 13387 & 13387 & 13387 & 13387 & 13387 & 13387 \\
& Order quantity & 80322 & 0 & 0 & 0 & 0 & 0 \\
\hline \multirow{2}{*}{ Plat baja 1,5 mm } & Demand & 3033 & 3033 & 3033 & 3033 & 3033 & 3033 \\
& Order quantity & 3033 & 3033 & 3033 & 3033 & 3033 & 3033 \\
\hline \multirow{2}{*}{ Kawat baja 3 mm } & Demand & 263 & 263 & 263 & 263 & 263 & 263 \\
& Order quantity & 1578 & 0 & 0 & 0 & 0 & 0 \\
\hline \multirow{2}{*}{ Kawat baja 4 mm } & Demand & 478 & 478 & 478 & 478 & 478 & 478 \\
& Order quantity & 2868 & 0 & 0 & 0 & 0 & 0 \\
\hline \multirow{2}{*}{ Kawat baja 4,5 mm } & Demand & 12 & 12 & 12 & 12 & 12 & 12 \\
& Order quantity & 72 & 0 & 0 & 0 & 0 & 0 \\
\hline
\end{tabular}

Dari hasil perhitungan diperoleh ukuran lot pemesanan yang menghasilkan ongkos total persediaan sebesar Rp. 54.109.030 dengan produksi komponen setiap periode harus terpenuhi agar target produksi tercapai dan menghindari biaya simpan yang tinggi serta pemesanan bahan baku dilakukan sekali pesan pada awal periode untuk memenuhi kebutuhan produksi seluruh periode. Kecuali pemesanan plat baja 1,5 $\mathrm{mm}$ yang dipesan 6 kali. Adanya perbedaan tersebut dikarenakan adanya hasil perhitungan dari metode Algoritma Wagner Within yang mengharuskan pemesanan dilakukan pada periode-periode tertentu.
Algoritma Wagner Within memberikan solusi optimum bagi persoalan ukuran pemesanan dinamis deterministik pada suatu kurun waktu tertentu dimana kebutuhan pada seluruh periode harus terpenuhi. Metode ini ditentukan dengan menggunakan program linier untuk memperoleh segi pemesanan yang optimum pada seluruh kebutuhan bersih sehingga semua kemungkinan pemesanan lot dihitung ongkos totalnya. Metode ini dikatakan metode yang paling optimum karena perhitungan penentuan ukuran lotnya didasarkan pada program dinamis yaitu suatu model matematis yang solusinya menjamin hasil perhitungan tersebut adalah hasil yang optimum. 
Tabel 9. Total biaya persediaan terendah komponen Mbox

\begin{tabular}{|c|c|c|}
\hline Nama Item & $\begin{array}{c}\text { Biaya } \\
\text { Persediaan } \\
\text { Terendah }\end{array}$ & $\begin{array}{c}\text { Waktu } \\
\text { produksi } \\
\text { (bulan) }\end{array}$ \\
\hline Mbox & Rp 1.800 .000 & 6 \\
\hline Tutup lengkap & Rp 3.000.000 & 6 \\
\hline Badan lengkap & $\mathrm{Rp} 2.400 .000$ & 6 \\
\hline Lapisan tutup & Rp 2.400 .000 & 6 \\
\hline Plat pengunci & Rp 3.000 .000 & 6 \\
\hline Tutup Mbox & Rp 1.800 .000 & 6 \\
\hline Rumah penjinjing & Rp 2.000.000 & 6 \\
\hline Pegangan penjinjing & Rp 2.400 .000 & 6 \\
\hline Engsel tutup & Rp 1.800 .000 & 6 \\
\hline Dinding badan & Rp 1.800 .000 & 6 \\
\hline Plat dasar & Rp 1.800 .000 & 6 \\
\hline Engsel badan & Rp 3.000 .000 & 6 \\
\hline Penahan kunci & Rp 1.800 .000 & 6 \\
\hline Pegangan & Rp 2.400 .000 & 6 \\
\hline Rumah pengunci & Rp 1.800 .000 & 6 \\
\hline Penyambung penjinjing & Rp 2.000 .000 & 6 \\
\hline Pena engsel & Rp 1.800 .000 & 6 \\
\hline Kawat pengunci & Rp 1.800 .000 & 6 \\
\hline $\begin{array}{l}\text { Total biaya persediaan } \\
\text { komponen } M b o x\end{array}$ & Rp 38.800.000 & \\
\hline
\end{tabular}

Tabel 10. Total biaya persediaan terendah bahan baku Mbox

\begin{tabular}{|c|c|c|}
\hline Nama Item & $\begin{array}{c}\text { Biaya } \\
\text { Persediaan } \\
\text { Terendah }\end{array}$ & $\begin{array}{l}\text { Waktu Pesan } \\
\text { (sekali pesan) }\end{array}$ \\
\hline Plat baja $0,5 \mathrm{~mm}$ & $\operatorname{Rp} 2.221 .250$ & 1 \\
\hline Plat baja $1 \mathrm{~mm}$ & Rp 2.221.250 & 1 \\
\hline Plat baja $1,5 \mathrm{~mm}$ & Rp 4.800.000 & 6 \\
\hline Kawat baja $3 \mathrm{~mm}$ & Rp 1.591.630 & 1 \\
\hline Kawat baja $4 \mathrm{~mm}$ & Rp 3.738.780 & 1 \\
\hline Kawat baja $4,5 \mathrm{~mm}$ & Rp 736.120 & 1 \\
\hline $\begin{array}{l}\text { Total biaya persediaan } \\
\text { bahan baku Mbox }\end{array}$ & Rp 15.309.030 & \\
\hline
\end{tabular}

Selain itu pemilihan metode Algoritma Wagner Within didasari atas perhitungan yang dapat menghasilkan biaya minimal dimana pada penelitian ini total biaya dapat di minimasi dengan adanya penurunan pada biaya simpan dan biaya pesan.

\section{Kesimpulan}

Berdasarkan penelitian yang telah dilakukan, maka dapat disimpulkan bahwa target produksi Mbox tidak dapat tercapai dikarenakan perencanaan dan pengendalian persediaan yang kurang optimal. Adapun pemecahan permasalahan perencanaan kebutuhan komponen serta bahan baku untuk memenuhi permintaan Mbox sebagai produk pendukung amunisi dengan total permintaan sebanyak 36000 Mbox dapat menggunakan teknik lotting yang mampu memberikan total biaya paling minimum yaitu dengan Algoritma Wagner Within.

Jenis bahan baku serta komponen dalam membentuk satu unit produk Mbox terdiri dari 18 jenis komponen serta 6 jenis bahan baku. Berdasarkan dari pembahasan perhitungan perencanaan dan pengendalian persediaan dengan menerapkan metode Algoritma Wagner Within diperoleh jumlah dan waktu pemesanan yang optimal untuk dapat mencapai target produksi yakni komponen harus diproduksi sesuai dengan jadwal dan jumlah yang sudah ditentukan yaitu sebanyak 6 kali produksi dengan jumlah sesuai dengan hasil perencanaan. Sedangkan bahan baku harus dipesan diawal semua untuk memenuhi kebutuhan produksi setiap periode. Kecuali pada pemesanan plat baja $1,5 \mathrm{~mm}$ yang dipesan 6 kali. Adanya perbedaan tersebut dikarenakan adanya hasil perhitungan dari metode Algoritma Wagner Within yang mengharuskan pemesanan dilakukan pada periode-periode tertentu. Sedangkan total biaya yang dikeluarkan untuk memenuhi kebutuhan persediaan Mbox pada 6 periode ini adalah sebesar Rp. 54.109.030. Penelitian selanjutnya diharapkan dapat menambah metode lot sizing lainnya agar mendapat perbandingan hasil yang paling optimal.

\section{Ucapan Terima Kasih}

Pada kesempatan kali ini, penulis ingin mengucapkan ucapan terima kasih terhadap beberapa pihak yang turut memberikan bimbingan, dukungan, bantuan, dan semangat. Penulis mengucapkan terima kasih kepada:

1. Bapak Teguh Oktiarso, ST., MT selaku dosen pembimbing akademik dan dosen pembimbing utama yang telah banyak memberikan masukan, nasehat, dan bimbingan selama penulis melakukan penelitian.

2. Bapak Purnomo, S.T., M.T selaku dosen pembimbing akademik dan dosen pembimbing dua yang juga turut serta 
memberikan bimbingan dan nasehat selama penulis melakukan penelitian.

3. Bapak Suranto, Bapak Taufik, Bapak Suli dan Bapak Aris selaku pembimbing lapangan di PT. X departemen produksi yang telah memberikan izin penulis untuk melakukan penelitian.

4. Bapak Witono dan Ibu Mujiati yang selalu memberikan doa, bantuan, semangat, dan dukungan baik secara moril maupun material.

5. Rida Arofah yang selalu memberikan dukungan, motivasi, dan semangat selama penelitian.

\section{Referensi}

[1] Ampuh, R., 2009, Manajemen Pabrik: Pendekatan Sistem untuk Efisiensi dan Efektivitas, Edisi 1, Bumi Aksara, Jakarta.

[2] Assauri, S., 2008, Manajemen Operasi dan Produksi, Edisi revisi 2008, Lembaga FE-UI, Jakarta.

[3] Tampubolon, M., 2004, Manajemen Operasional, Ghalia Indonesia, Jakarta.

[4] Tersine, R. J., 1993, Principles of Inventory and Materials Management, edisi 4, Prentice Hall. 